Article

\title{
Evolution of Tuberculosis/Human Immunodeficiency Virus Services among Different Integrated Models in Myanmar: A Health Services Review
}

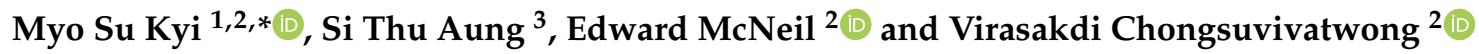 \\ 1 Regional Public Health Department, Nay Pyi Taw Union Territory 15011, Myanmar \\ 2 Epidemiology Unit, Faculty of Medicine, Prince of Songkla University, Hat Yai, Songkhla 90110, Thailand; \\ edward.m@psu.ac.th (E.M.); cvirasak@medicine.psu.ac.th (V.C.) \\ 3 National Tuberculosis Programme, Ministry of Health and Sports, \\ Nay Pyi Taw Union Territory 15011, Myanmar; dr.sta.ntp@gmail.com \\ * Correspondence: drmyosukyi@gmail.com; Tel.: +95-9-5049099
}

Received: 23 November 2018; Accepted: 21 December 2018; Published: 24 December 2018

\begin{abstract}
Myanmar is one of the highly affected countries by tuberculosis (TB) and human immunodeficiency virus (HIV) co-infection. We aimed to review the coverage of TB/HIV integrated services as well as to document the performance of this integrated services. A retrospective program review was conducted using the aggregated data of the National TB Programme (NTP) from 2005 to 2016. In Myanmar, TB/HIV services were initiated in seven townships in 2005. Townships were slowly expanded until 2013. After that, the momentum was increased by increasing the government budget allocation for NTP. In 2016, the whole country was eventually covered by TB/HIV services in different types of integration. Antiretroviral therapy (ART) coverage among HIV-positive TB patients remained low and it was the only significant difference among the three types of integration. Barriers of low ART coverage need to be investigated to reduce the burden of TB/HIV.
\end{abstract}

Keywords: tuberculosis/human immunodeficiency virus; integrated services; ART; Myanmar

\section{Introduction}

Myanmar, a country located in South-East Asia, is one of the 30 high tuberculosis (TB) burden countries with a prevalence (bacteriologically positive TB) of $434 / 100,000$ population according to the National TB Prevalence Survey in 2010 [1]. The prevalence of human immunodeficiency virus (HIV) in some areas of Myanmar is among the highest in the Asia-Pacific region and the estimated HIV prevalence at the national level was 0.59\% among those aged 15 years or more in 2015 [2]. Consequently, Myanmar has become one of the countries mostly affected by TB/HIV co-infection. In 2016, of 139,625 TB patients notified, 10,952 were living with HIV [3].

To alleviate the dual burden of TB/HIV in populations at risk, the World Health Organization (WHO) developed policies and guidelines for TB/HIV services [4]. Integration of $\mathrm{TB} / \mathrm{HIV}$ services improve the health outcomes of TB/HIV co-infected patients with the benefits of timely ART uptake [5-10], increased uptake of HIV testing and CPT [7,11-14] and better TB treatment outcomes $[7,12,14-17]$. Although it is recommended to extend further integration of services, the two programs for TB and HIV in most countries remain separated with their own implementation strategies and funding flows. Thus, the integration of these two programs encounters challenges from policy making to integration at the implementation level [18].

In Myanmar, the National TB Programme (NTP) and National AIDS Programme (NAP) are vertical programs under the Ministry of Health and Sports. In 2016, the NTP was operating with 
14 regional/state TB centers and $101 \mathrm{~TB}$ teams at district and township levels. The whole country has been covered with Directly Observed Treatment, Short Course (DOTS) since 2003. The NAP was operating with 113 antiretroviral therapy (ART) centers and 140 decentralized ART clinics across the country. ART started in 2005 but up until now does not cover the whole country.

TB and HIV control activities in Myanmar are supported by the government along with a number of international donor organizations [19], the largest support coming from the Global Fund to fight AIDS, Tuberculosis and Malaria (GFATM) [2,20]. In 2013, the GFATM launched a new funding model that served as an instrument towards identifying key populations, developing the single proposal (concept note) for TB and HIV to enhance joint programming and integrated implementation of activities [21].

Following the WHO policy, TB/HIV collaborative services have been implemented since 2005 in Myanmar. There is thus a need to review the progress of TB/HIV services over the past decade. The objectives of this study are to review the coverage of TB/HIV integrated services and to document the performance of TB/HIV services in Myanmar.

\section{Materials and Methods}

\subsection{Study Design and Data Sources}

A retrospective program review was conducted using the aggregated data extracted from routine surveillance reports of the NTP. Table 1 defines the WHO recommended core indicators representing the performance of activities which are implemented by the NTP [22,23]. Our study used these three core indicators as a conventional assessment of the performance of TB/HIV services.

Table 1. WHO recommended core indicators for performance of tuberculosis/human immunodeficiency virus (TB/HIV) services. CPT: cotrimoxazole preventive therapy.

\begin{tabular}{lll}
\hline \multicolumn{1}{c}{ Core Indicator } & \multicolumn{1}{c}{ Numerator } & \multicolumn{1}{c}{ Denominator } \\
\hline $\begin{array}{l}\text { Proportion of TB patients with } \\
\text { known HIV status }\end{array}$ & $\begin{array}{l}\text { Number of TB patients registered } \\
\text { during the reporting period that had } \\
\text { a HIV test result and recorded in the } \\
\text { TB register. }\end{array}$ & $\begin{array}{l}\text { Total number of TB patients } \\
\text { registered during the } \\
\text { reporting period. }\end{array}$ \\
\hline $\begin{array}{l}\text { Proportion of HIV-positive TB } \\
\text { patients who received CPT }\end{array}$ & $\begin{array}{l}\text { Number of HIV-positive TB patients, } \\
\text { registered over the reporting period, } \\
\text { starting or continuing CPT } \\
\text { treatment during their TB treatment. }\end{array}$ & $\begin{array}{l}\text { Total number of HIV positive TB } \\
\text { patients registered during the } \\
\text { reporting period. }\end{array}$ \\
\hline $\begin{array}{l}\text { Proportion of HIV-positive TB } \\
\text { patients who received ART }\end{array}$ & $\begin{array}{l}\text { Number of HIV-positive TB patients } \\
\text { registered over the reporting period } \\
\text { starting or continuing ART } \\
\text { treatment during their TB treatment. }\end{array}$ & $\begin{array}{l}\text { Total number of HIV positive TB } \\
\text { patients registered during the } \\
\text { reporting period. }\end{array}$ \\
\hline
\end{tabular}

\subsection{Data Analysis}

To describe the changes over time, trends were fitted on a logarithmic scale due to the highly skewed distribution of the data. A Joinpoint regression model was used to estimate the regression coefficients with a joinpoint between the government budget allocation and TB/HIV township expansion. Joinpoint regression model is a well-known approach used to study varying trends over time that identifies the time point(s) in which the trend significantly changes, and estimates the regression function with joinpoint(s) previously identified [24,25]. The performance of TB/HIV services are summarized using the median and interquartile range (IQR). The Pearson product-moment correlation coefficient was calculated to assess the strength of linear association between the proportions of each core performance indicator. The Kruskal-Wallis test was used to quantify the difference in the performance of each type of integration with significance level set at 0.05 . All analyses were conducted using R version 3.5.1 (https:/ / cran.r-project.org). 
For trend analysis, we used the compiled data of government and non-government sectors. For analysis of performance among different types of integration in the year when the whole country was covered by TB/HIV services, we used the data of government sector only because the nature of the services provided by the non-government sector was not well identified.

\subsection{Ethics}

The study was approved by the Ethical Review Committees from Prince of Songkla University, Thailand (REC Number: 59-278-18-5) and the Department of Medical Research, Myanmar.

\section{Results}

\subsection{Evolution of TB/HIV Services}

In Myanmar, the Central Coordinating Body for TB/HIV services was organized in 2005 and strengthened in 2012 with the guidance of the Ministry. This coordinating body was established at state/regional, district and township levels to be functioning according to the scale-up plan of TB/HIV townships. TB/HIV services were initiated in seven townships in 2005 and expanded to 136, 236, and 330 townships by 2014, 2015, and 2016, respectively.

In townships which implement the fully integrated model, TB and HIV services are provided at township hospitals managed by the township medical officers. A partially integrated model is provided using two approaches. One approach is that both vertical teams coexist in the same township, referring cases to each other for the services not available in the referring center. The second approach is to have only TB services; patients with HIV are referred to an HIV clinic in the nearest township.

Figure 1 demonstrates the number of townships in different types of integration from 2005 to 2016. Partially integrated model in both approaches were initiated in 2005. In 2013, the fully integrated model was introduced and all seven townships that were previously classified as using the partially integrated model with only TB services became fully integrated townships. Between 2013 and 2016, all three groups showed an increase in the number.

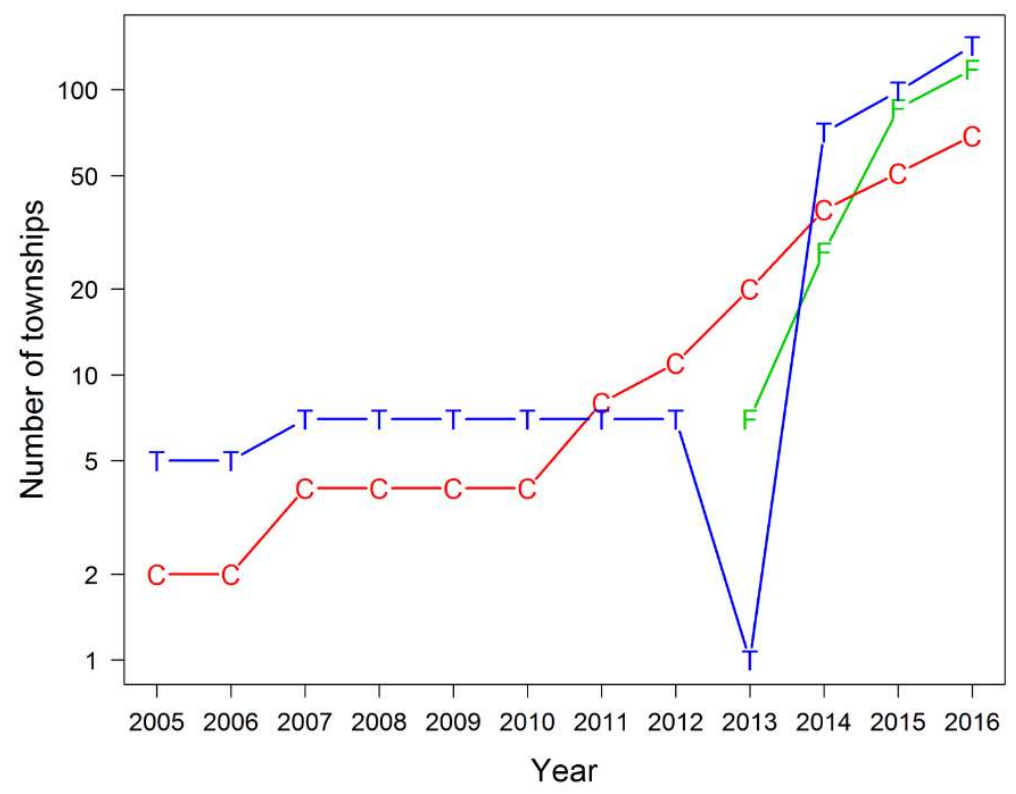

Figure 1. Number of townships in different types of integrated TB/HIV services (2005-2016). F = fully integrated model; $\mathrm{C}$ = partially integrated model: TB and HIV services co-existed; $\mathrm{T}=$ partially integrated model: TB services only.

Figure 2 shows the relationship between government budget allocation for the NTP and total number of townships with TB/HIV services between 2003 and 2016. The relationship is evident from 
the joinpoint regression showing two clear periods with vastly differing slopes with a breakpoint at 2013. During the first period (before 2013), the relationship was not significant. Since 2013, there was an average of 1.4 townships established for every 10 million kyats allocated from the budget.

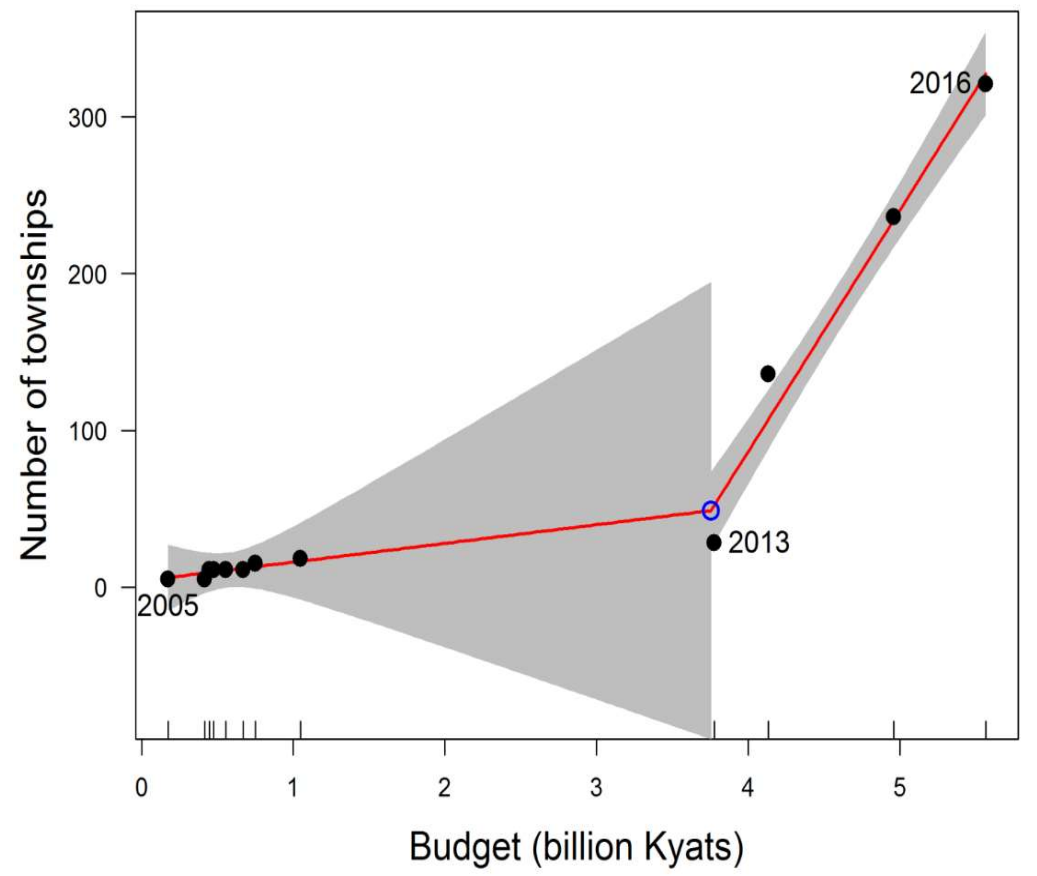

Figure 2. Relationship between government budget allocation for National TB Programme (NTP) and number of TB/HIV townships (2005-2016) using Joinpoint regression. Note: The grey shading represents $95 \%$ confidence interval of the estimated value.

\subsection{Performance of TB/HIV Services}

$\mathrm{TB} / \mathrm{HIV}$ services which are provided at different integrated models in Myanmar are summarized in Table 2. Items of services are described in the first column. Under a fully integrated model of care, the same clinic offers all services for TB and HIV patients (second column). Under a partially integrated model of care, TB clinics (third column) offer all services related to TB and HIV counseling and testing service but refer those with HIV co-infection to an HIV clinic for ART and cotrimoxazole preventive therapy (CPT). HIV clinics (last column) offer all care and supports for people living with HIV, including TB symptom screening and provision of IPT (isoniazid preventive therapy), but refer those presumptive of TB to TB clinics for further necessary management. A cross-referral system between the NTP and NAP has been developed and the recording and reporting framework is standardized. Both TB and HIV programmes use patient cards as the data source for paper-based registers. TB and HIV clinics separately report summaries of TB/HIV collaborative services to the respective programmes at the central level where data are compiled quarterly in an electronic system.

Figure 3 shows the conventional assessment of the performance of TB/HIV services from 2005 to 2016. The trends of all services varied across years. The percentage of TB patients with known HIV status markedly increased from 27\% (95\% CI: 25.2-29.7) in 2005 to 82\% (95\% CI: 81.6-82.0) in 2016. Similarly, the proportion of HIV-positive TB patients who received ART has markedly increased from 6\% (95\% CI: 1.5-13.6) in 2005 to 58\% (95\% CI: 57.1-59.0) in 2016. All rates decreased between 2011 and 2014. 
Table 2. Availability of Services for TB/HIV co-infected patients.

\begin{tabular}{|c|c|c|c|}
\hline \multirow{2}{*}{ Services } & \multirow{2}{*}{$\begin{array}{l}\text { Fully Integrated Model } \\
\qquad(118+)\end{array}$} & \multicolumn{2}{|c|}{$\begin{array}{l}\text { Partially Integrated Model } \\
\qquad(212+)\end{array}$} \\
\hline & & TB Clinics & HIV Clinics \\
\hline \multicolumn{4}{|l|}{ HIV services } \\
\hline HIV counseling and testing & + & + & + \\
\hline ART provision & + & Refer to HIV clinic & + \\
\hline CPT provision & + & Refer to HIV clinic & + \\
\hline \multicolumn{4}{|l|}{ TB services } \\
\hline TB symptom screening & + & + & + \\
\hline $\begin{array}{l}\text { Diagnosis and treatment of TB } \\
\text { (including Xpert MTB/RIF * assay) }\end{array}$ & + & + & Refer to TB clinic \\
\hline IPT provision & + & + & + \\
\hline
\end{tabular}

† Number of townships with the specific integrated model in 2016; ${ }^{*}$ Mycobacterium tuberculosis/resistance to rifampicin; TB: tuberculosis; HIV: human immunodeficiency virus; ART: antiretroviral therapy; CPT: cotrimoxazole preventive therapy; IPT: isoniazid preventive therapy.

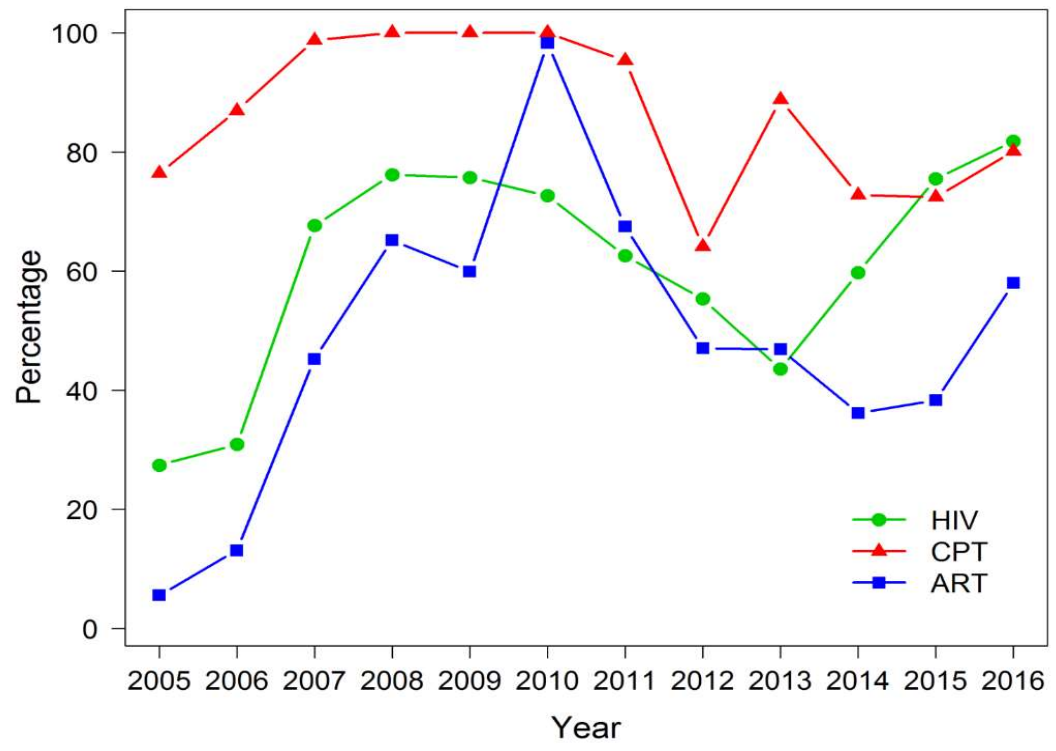

Figure 3. Performance of TB/HIV services including government and non-government sector (2005-2016). HIV: TB patients with known HIV status; CPT: HIV-positive TB patients who received CPT; ART: HIV-positive TB patients who received ART.

Because this type of performance monitoring might give misleading information, Figure 4 describes the trends of TB/HIV service cascade in a logarithmic scale from 2005 to 2016. The number of registered TB cases increased each year, of which cases with known HIV status also increased. The narrowest gap between these two trends was observed in 2016. Among TB patients with known HIV status, the proportion of HIV-positive cases eventually reduced in 2016 as the gap between the two series widened. The gap between HIV-positive TB cases and those who received CPT consistently narrowed while the gap between HIV positive TB cases who received ART were initially wide and eventually narrowed. 


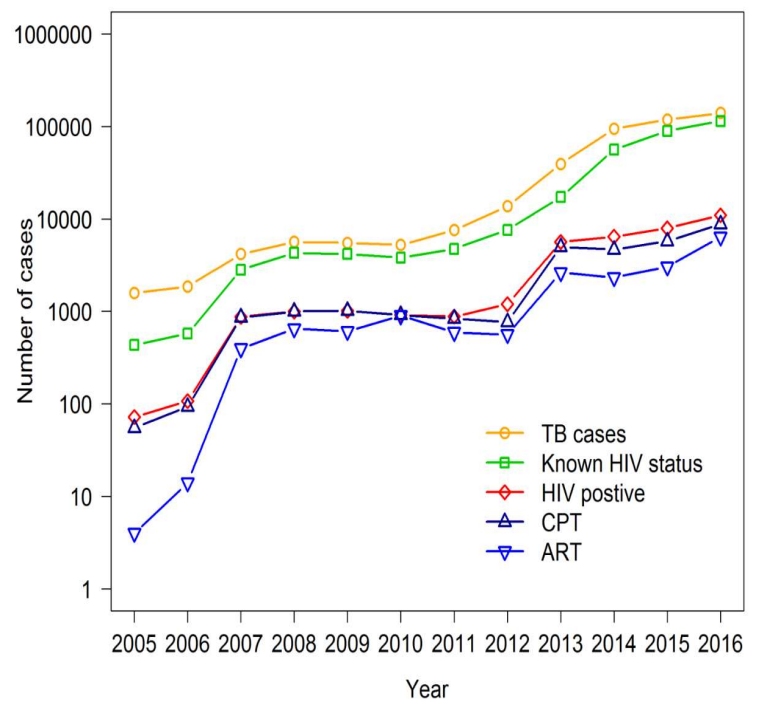

Figure 4. Trends of TB/HIV service cascade in number of cases (2005-2016). Note: Data included government and non-government sector. CPT: HIV-positive TB patients who received CPT; ART: HIV-positive TB patients who received ART.

An evaluation of the performance of TB/HIV services according to states/regions in 2016, when the coverage in the whole country was $100 \%$, is shown in Figure 5. The proportions of all three services were significantly correlated with each other, with the Pearson product-moment correlation coefficient, between HIV testing and CPT of 0.62 , between HIV testing and ART of 0.53 , and between CPT and ART of 0.65. Low rates of services were observed consistently in Rakhine State while high rates were observed in Yangon, Mandalay and Nay Pyi Taw Regions.
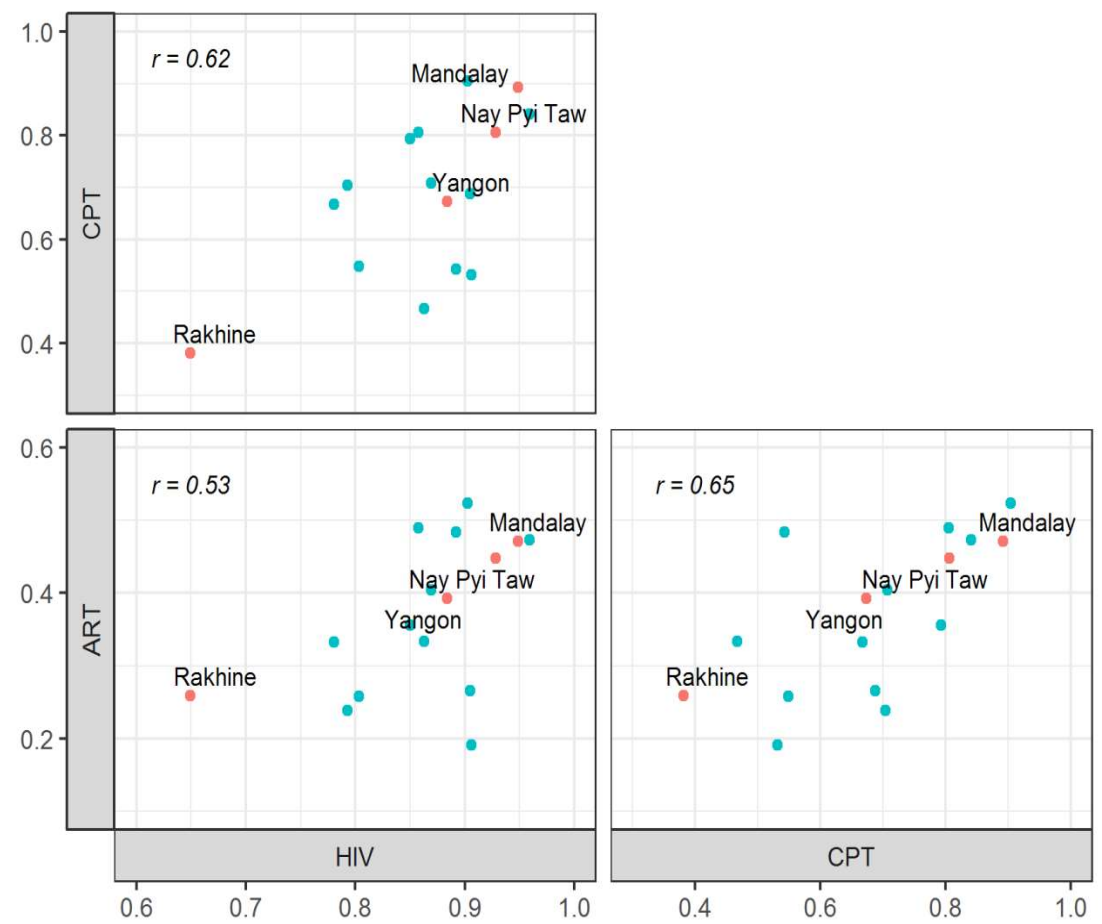

Figure 5. Correlations between the three recommended core performance indicators for TB/HIV services in the 15 states/regions of Myanmar in 2016. Note: Data included only government sector. The highlighted points correspond to regions with low performance (Rakhine) or high development. HIV: TB patients with known HIV status; CPT: HIV-positive TB patients who received CPT; ART: HIV-positive TB patients who received ART; $r$ : Pearson product-moment correlation coefficient. 
Table 3 shows a comparison of the performance of TB/HIV services by the three different integrated models in 2016. The only significant difference was observed on the percentage of HIV-positive TB patients who received ART, which was more common in the partially integrated model with TB and HIV services co-existed (Kruskal-Wallis test, $p$ value $=0.02$ ). However, ART coverage among TB/HIV co-infected patients was low across all types of integration, accounting for less than $50 \%$.

Table 3. Median (interquartile range (IQR)) percentage of target patients who received the specific service from government sector by different integrated models in 2016.

\begin{tabular}{|c|c|c|c|c|}
\hline \multicolumn{5}{|c|}{$\begin{array}{c}\text { Integrated Model } \\
\text { Partial }\end{array}$} \\
\hline & Full & $\begin{array}{l}\text { TB and HIV } \\
\text { co-Existed }\end{array}$ & TB Only & $p$ Value $\dagger$ \\
\hline $\begin{array}{l}\text { TB patients with known } \\
\text { HIV status }\end{array}$ & 93 (77.9-98.1) & 93 (82.5-98.6) & $90(76.3-98.5)$ & 0.63 \\
\hline $\begin{array}{l}\text { HIV-positive TB patients } \\
\text { who received CPT }\end{array}$ & $81(50.0-100)$ & $82(62.2-91.1)$ & $74(33.3-100)$ & 0.43 \\
\hline $\begin{array}{l}\text { HIV-positive TB patients } \\
\text { who received ART }\end{array}$ & $32(19.4-50.0)$ & $45(28.4-59.0)$ & $33(8.3-57.1)$ & 0.02 \\
\hline
\end{tabular}

+ Kruskal-Wallis test.

\section{Discussion}

We conducted a study in Myanmar with the aims to review the coverage of TB/HIV integrated services and to document the performance of TB/HIV services. In Myanmar, TB/HIV services were initiated in seven townships in 2005 and the whole country was covered by 2016, 11 years later. The performance of TB/HIV services was found to increase over these 11 years. The proportion of HIV-positive TB patients who received ART was low across all models. In 2016, Rakhine State had the lowest rates of all services, whilst Yangon, Mandalay and Nay Pyi Taw achieved the high rates.

Townships for TB/HIV services were slowly expanded until 2013 without significantly associated with the government budget allocation for NTP. After that, the momentum was increased by increasing budget allocation. This finding may have more explanations. TB/HIV townships expansion did not depend solely on the expenditure of the NTP. Because of two vertical programs' collaboration for TB/HIV services, it relied also on the NAP side, especially for provision of ART. The NAP introduced decentralized ART clinics at township level hospitals in 2013 and then expanded geographically [2]. Furthermore, the new funding model of the GFATM, initiated in 2013, may have contributed to that achievement. With similar explanations, the fully integrated model could be started in 2013.

On assessment of the performance based on the proportions of cases adhering to the WHO core performance indicators for each of the services, there was a period when all services appeared to show a decline. However, after viewing the trends on a logarithmic scale, the performance of all services was satisfactory throughout the 12 year period. This suggests that using the proportions of services to assess the performance over time may be invalid, especially at the time when services are being expanded, although it is useful as indicators for assessment of target achievement.

ART coverage represents the level of HIV care and support to TB/HIV patients. WHO recommends that ART should be provided for all HIV-positive TB patients [4]. Globally, about $85 \%$ of notified HIV-positive TB patients were reported to be on ART in 2016 [26]. However, in our study, the highest rate of ART coverage, observed in 2016, was only 58\%. ART coverage was less than $50 \%$ across all types of integration on analysis of the data from only government sector in 2016 . It might be due to the limitation which did not include the data from non-government sector that contributed about 19\% of all TB notifications in 2016 [3]. The HIV testing rate was enhanced and the 
achievement in 2016 (82\%) was appreciable compared with the global rate (57\%) [26]. In this study, CPT coverage was the best among all services.

In 2016 when the services started to cover the whole country, Rakhine State was observed to have the lowest performance across all services. Rakhine State is located in the west of Myanmar bordering Bangladesh. A series of violent clashes have been ongoing for many years which have subsequently affected the health care services in Rakhine State. The most developed regions, such as Yangon, Mandalay and Nay Pyi Taw, had high performances across all services. ART coverage was observed the highest in the partially integrated townships with both vertical teams, possibly due to the higher level of expertise and capacity of the clinic staff to manage patients with TB and HIV. Another explanation might be due to HIV patients having easy access to ART services because the townships are regional/state or district level townships.

Fully integrated model is likely to benefit patients by having lower transportation costs if visits for TB and HIV are at the same clinic on the same day [27] and reduce the referral problems between TB and HIV clinics [28]. However, it might require the additional resources and expertise of staff for implementation of fully integrated model [27]. Besides, TB transmission is a risk at the place where both TB and HIV patients attend [29,30]. Our study has limited information on challenges and opportunities of different integration services. This conjecture needs to be evidenced by further studies.

\section{Conclusions}

Myanmar could expand well TB/HIV services. The performance of HIV testing and CPT provision was adequate. However, ART coverage among HIV-positive TB patients remained low across all types of integration. Barriers of low ART coverage need to be investigated to reduce the burden of TB/HIV.

Author Contributions: Conceptualization, M.S.K. and V.C.; Formal analysis, M.S.K., E.M. and V.C.; Investigation, M.S.K.; Methodology, M.S.K. and V.C.; Resources, M.S.K. and S.T.A.; Validation, M.S.K., S.T.A. and V.C.; Writing —original draft, M.S.K.; Writing—review and editing, S.T.A., E.M. and V.C.

Funding: This research was conducted through TB/MDR-TB research training program at Epidemiology unit, Prince of Songkla University under the support of Fogarty International Center, National Institute of Health (Grant number D43TW009522).

Conflicts of Interest: The authors declare no conflict of interest.

\section{References}

1. National TB Programme, Myanmar. Report on National Prevalent Survey 2009-2010, Myanmar. 2010. Available online: http://www.searo.who.int/myanmar/documents/TB_Prevelence_Survey_report.pdf (accessed on 7 December 2011).

2. National AIDS Programme, Myanmar. National Strategic Plan on HIV and AIDS, Myanmar (2016-2020). Available online: https://www.aidsdatahub.org/sites/default/files/highlight-reference/document/ Myanmar_National_Strategic_Plan_on_HIV_and_AIDS_2016-2020.pdf (accessed on 12 December 2016).

3. Annual Report 2016, National Tuberculosis Programme Myanmar. National TB Programme, Myanmar. 2018. Available online: https:/ / myanmarhscc.org/wp-content/uploads/2016/12/2008.pdf (accessed on 12 December 2016).

4. World Health Organization. WHO Policy on Collaborative TB/HIV Activities: Guidelines for National Programmes and Other Stakeholders; WHO: Geneva, Switzerland, 2012.

5. Pfeiffer, J.; Montoya, P.; Baptista, A.J.; Karagianis, M.; Pugas Mde, M.; Micek, M.; Johnson, W.; Sherr, K.; Gimbel, S.; Baird, S.; et al. Integration of HIV/AIDS services into African primary health care: Lessons learned for health system strengthening in Mozambique-A case study. J. Int. AIDS Soc. 2010, 13, 3. [CrossRef] [PubMed]

6. Owiti, P.; Zachariah, R.; Bissell, K.; Kumar, A.M.V.; Diero, L.; Carter, E.J.; Gardner, A. Integrating tuberculosis and HIV services in rural Kenya: Uptake and outcomes. Public Health Action 2015, 5, 36-44. [CrossRef] [PubMed] 
7. Hermans, S.M.; Castelnuovo, B.; Katabira, C.; Mbidde, P.; Lange, J.M.A.; Hoepelman, A.I.M.; Coutinho, A.; Manabe, Y.C. Integration of HIV and TB Services Results in Improved TB Treatment Outcomes and Earlier Prioritized ART Initiation in a Large Urban HIV Clinic in Uganda. J. Acquir. Immune Defic. Syndr. 2012, 60, e29-e35. [CrossRef] [PubMed]

8. Kerschberger, B.; Hilderbrand, K.; Boulle, A.M.; Coetzee, D.; Goemaere, E.; De Azevedo, V.; Cutsem, G.V. The Effect of Complete Integration of HIV and TB Services on Time to Initiation of Antiretroviral Therapy: A Before-After Study. PLoS ONE 2012, 7, e46988. [CrossRef] [PubMed]

9. Pathmanathan, I.; Pasipamire, M.; Pals, S.; Dokubo, E.K.; Preko, P.; Ao, T.; Mazibuko, S.; Ongole, J.; Dhlamini, T.; Haumba, S. High uptake of antiretroviral therapy among HIV-positive TB patients receiving co-located services in Swaziland. PLoS ONE 2018, 13, e0196831. [CrossRef] [PubMed]

10. Nash, D.; Tymejczyk, O.; Gadisa, T.; Kulkarni, S.G.; Hoffman, S.; Yigzaw, M.; Elul, B.; Remien, R.H.; Lahuerta, M.; Daba, S.; et al. Factors associated with initiation of antiretroviral therapy in the advanced stages of HIV infection in six Ethiopian HIV clinics, 2012 to 2013. J. Int. AIDS Soc. 2016, 19, 20637. [CrossRef] [PubMed]

11. Phiri, S.; Khan, P.Y.; Grant, A.D.; Gareta, D.; Tweya, H.; Kalulu, M.; Chaweza, T.; Mbetewa, L.; Kanyerere, H.; Weigel, R.; et al. Integrated tuberculosis and HIV care in a resource-limited setting: Experience from the Martin Preuss centre, Malawi: Integrated TB and HIV care in Malawi. Trop. Med. Int. Health 2011, 16, 1397-1403. [CrossRef]

12. Kapata, N.; Chanda-Kapata, P.; Grobusch, M.P.; O'Grady, J.; Schwank, S.; Bates, M.; Jansenn, S.; Mwinga, A.; Cobelens, F.; Mwaba, P.; et al. Scale-up of TB and HIV programme collaborative activities in Zambia-A 10-year review: Scale-up of TB and HIV programme collaborative activities. Trop. Med. Int. Health 2012, 17, 760-766. [CrossRef]

13. Pevzner, E.S.; Vandebriel, G.; Lowrance, D.W.; Gasana, M.; Finlay, A. Evaluation of the Rapid Scale-up of Collaborative TB/HIV Activities in TB Facilities in Rwanda, 2005-2009. BMC Public Health 2011, 11, 550. [CrossRef]

14. Ansa, G.A.; Walley, J.D.; Siddiqi, K.; Wei, X. Assessing the impact of TB/HIV services integration on TB treatment outcomes and their relevance in TB/HIV monitoring in Ghana. Infect. Dis. Poverty 2012, 1, 13. [CrossRef]

15. Schulz, S.A.; Draper, H.R.; Naidoo, P. A comparative study of tuberculosis patients initiated on ART and receiving different models of TB-HIV care. Int. J. Tuberc. Lung Dis. 2013, 17, 1558-1563. [CrossRef] [PubMed]

16. Miti, S.; Mfungwe, V.; Reijer, P.; Maher, D. Integration of tuberculosis treatment in a community-based home care programme for persons living with HIV/AIDS in Ndola, Zambia. Int. J. Tuberc. Lung Dis. 2003, 7, S92-S98. [PubMed]

17. Burnett, S.M.; Zawedde-Muyanja, S.; Hermans, S.M.; Weaver, M.R.; Colebunders, R.; Manabe, Y.C. Effect of TB/HIV Integration on TB and HIV Indicators in Rural Ugandan Health Facilities. J. Acquir. Immune Defic. Syndr. 2018, 79, 7. [CrossRef] [PubMed]

18. Friedland, G.; Harries, A.; Coetzee, D. Implementation Issues in Tuberculosis/HIV Program Collaboration and Integration: 3 Case Studies. J. Infect. Dis. 2007, 196, S114-S123. [CrossRef] [PubMed]

19. Theingi, P.; Harries, A.D.; Wai, K.T.; Shewade, H.D.; Saw, S.; Win, T.; Thein, S.; Kyi, M.S.; Nyunt Oo, H.; Aung, S.T. National scale-up of tuberculosis-human immunodeficiency virus collaborative activities in Myanmar from 2005 to 2016 and tuberculosis treatment outcomes for patients with human immunodeficiency virus-positive tuberculosis in the Mandalay Region in 2015. Trans. R. Soc. Trop. Med. Hyg. 2017, 111, 402-409. [CrossRef] [PubMed]

20. National TB Programme, Myanmar, National Strategic Plan for Tuberculosis, Myanmar (2016-2020). Available online: https://www.aidsdatahub.org/sites/default/files/publication/Myanmar_National_ Strategic_Plan_for_Tuberculosis_2016-2020.pdf (accessed on 22 December 2016).

21. Kunii, O.; Yassin, M.A.; Wandwalo, E. Investing to end epidemics: The role of the Global Fund to control TB by 2030. Trans. R. Soc. Trop. Med. Hyg. 2016, 110, 153-154. [CrossRef] [PubMed]

22. National TB Programme, Myanmar, National AIDS programme, Myanmar. Guidelines for the Programmatic management of TB/HIV in Myanmar. Available online: https://www.aidsdatahub.org/sites/default/ files/toolandguide/document/Myanmar_Guidelines_for_the_Management_of_Multidrug-Resistant_ Tuberculosis_2017.pdf (accessed on 15 February 2017). 
23. Kanchar, A.; Getahun, H.; Joint United Nations Programme on HIV/AIDS; United States, President's Emergency Plan for AIDS Relief; WHO Global TB Programme Ed. A Guide to Monitoring and Evaluation for Collaborative TB/HIV Activities; WHO: Geneva, Switzerland, 2015.

24. Kim, H.J.; Fay, M.P.; Feuer, E.J.; Midthune, D.N. Permutation tests for joinpoint regression with applications to cancer rates. Stat. Med. 2000, 19, 335-351. [CrossRef]

25. Pagan, E.; Rea, F.; Compagnoni, M.M.; Cantarutti, A.; Pugni, P.; Bagnardi, V.; Corrao, G. Joinpoint Regression Analysis with Time-on-Study as Time-Scale. Application to Three ITALIAN Population-Based Cohort Studies; Epidemiol Biostat and Public Health: Milano, Italy, 2017.

26. Organisation Mondiale de la Santé. Global Tuberculosis Report 2017; Organisation Mondiale de la Santé: Geneva, Switzerland, 2017.

27. Legido-Quigley, H.; Montgomery, C.M.; Khan, P.; Atun, R.; Fakoya, A.; Getahun, H.; Grant, A.D. Integrating tuberculosis and HIV services in low- and middle-income countries: A systematic review. Trop. Med. Int. Health 2013, 18, 199-211. [CrossRef] [PubMed]

28. Wandwalo, E.; Kapalata, N.; Tarimo, E.; Corrigan, C.B.; Morkve, O. Collaboration between the national tuberculosis programme and a non governmental organisation in TB/HIV care at a district level: Experience from Tanzania. Afr. Health Sci. 2004, 4, 6.

29. Dong, K.; Thabethe, Z.; Hurtado, R.; Sibaya, T.; Dlwati, H.; Walker, B.; Wilson, D. Challenges to the Success of HIV and Tuberculosis Care and Treatment in the Public Health Sector in South Africa. J. Infect. Dis. 2007, 196, S491-S496. [CrossRef]

30. Gandhi, N.R.; Moll, A.P.; Lalloo, U.; Pawinski, R.; Zeller, K.; Moodley, P.; Meyer, E.; Friedland, G. Tugela Ferry Care and Research (TFCaRes) Collaboration. Successful Integration of Tuberculosis and HIV Treatment in Rural South Africa: The Sizonq'oba Study. J. Acquir. Immune Defic. Syndr. 2008, 50, 37-43. [CrossRef] [PubMed]

(C) 2018 by the authors. Licensee MDPI, Basel, Switzerland. This article is an open access article distributed under the terms and conditions of the Creative Commons Attribution (CC BY) license (http:/ / creativecommons.org/licenses/by/4.0/). 